\title{
Melatonin and the development of circadian and seasonal rhythmicity
}

\author{
I. C. McMillen ${ }^{1}$, D. C. Houghton ${ }^{1}$ and I. R. Young ${ }^{2}$ \\ Departments of Physiology, ${ }^{\mathrm{I}}$ The University of Adelaide, South Australia and ${ }^{2}$ Monash University, \\ Clayton, Victoria, Australia
}

\begin{abstract}
We have investigated whether the maternal melatonin rhythm provides the fetus with either a circadian or seasonal 'signal' during development. Our findings provide evidence that melatonin can generate and entrain the early evening peak in the daily rhythm of fetal breathing movements. In contrast, daily variations in maternal and fetal prolactin concentrations are present in pinealectomized ewes, are altered by changes in the time of onset of darkness, but are unaltered by changes in the phase of the daily melatonin rhythm. The mechanisms that generate and control the daily prolactin rhythm before and after birth are therefore unknown. It is clear from a number of studies that the duration of the nocturnal melatonin signal provides the adult and fetal sheep with photoperiodic information. We investigated whether there are differences in the fetal plasma concentrations of prolactin in ewes held in long and short photoperiods after surgical disconnection of the fetal hypothalamus and pituitary and demonstrated that there was a fetal prolactin response to the external photoperiod in sheep fetuses in which the hypothalamopituitary axis was either intact or surgically disconnected. We have suggested that one potential extrahypothalamic site of action of maternal melatonin is at the pars tuberalis of the fetal pituitary. It appears therefore that there are a number of different mechanisms for the neuroendocrine transmission of information about the time of day and duration of the external photoperiod to the sheep fetus throughout late gestation.
\end{abstract}

\section{Introduction}

Although the fetus spends gestation sequestered in the darkness of the womb, it has recently become clear that there are a number of different signals that provide the fetus with information about the time of day, and in some cases, the time of year. There are, for instance, a range of daily rhythms in behaviour (for example in the incidence of fetal breathing movements) and in hormone concentrations (for example melatonin and prolactin) which have been measured in the sheep fetus during late gestation. The source and control of this daily rhythmicity in fetal life is not fully understood. Recently it has become clear that there is a relationship between the duration of the external photoperiod and the maternal and fetal plasma concentrations of prolactin throughout late gestation in sheep (Bassett et al., 1988). However, the neuroendocrine mechanisms involved in the transduction of this seasonal rhythm are also unclear. There is a daily rhythm in maternal and fetal plasma concentrations of melatonin in pregnant ewes and sheep fetuses during late gestation (Yellon and Longo, 1987; Zemdegs et al., 1988). As pinealectomy of the pregnant ewe abolishes the nocturnal increase in both maternal and fetal melatonin concentrations (Fig. 1), it has been considered that the fetal melatonin rhythm results from placental transfer of maternal melatonin (Yellon and Longo, 1988; Zemdegs et al., 1988; McMillen et al., 1989). It has been postulated that maternal melatonin provides the fetus with circadian or photoperiodic information and that this 


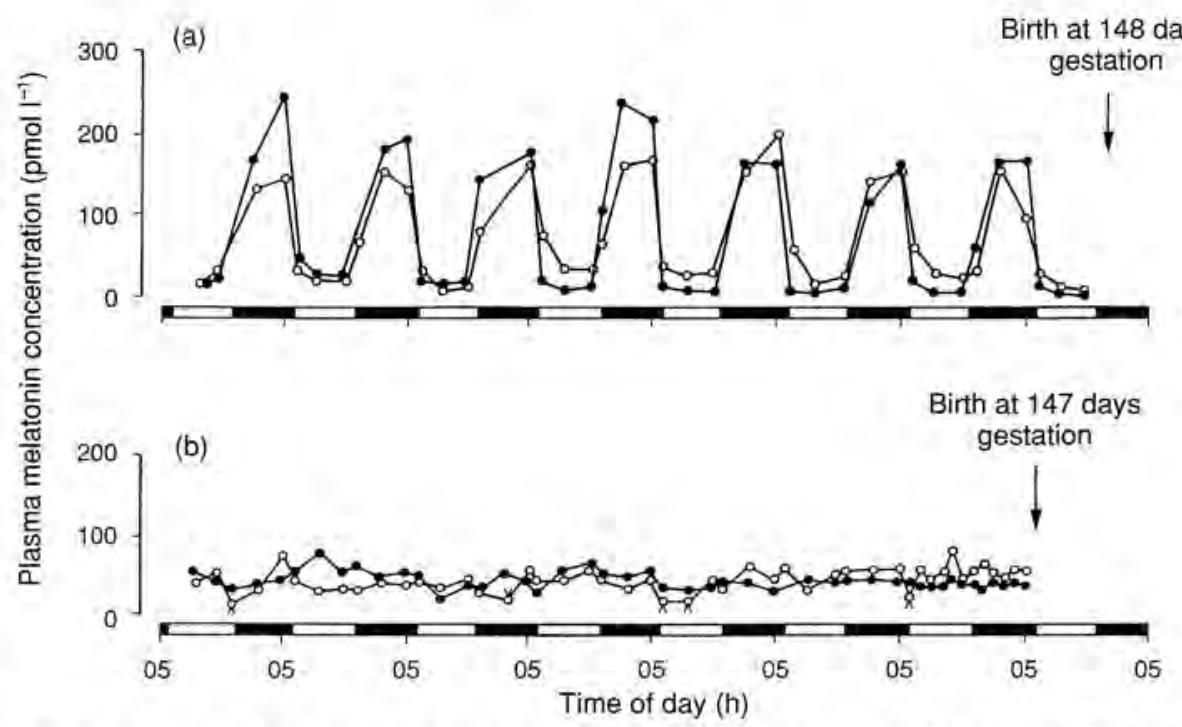

Fig. 1. Maternal $(\bullet)$ and fetal $(-)$ plasma melatonin concentrations during the last $7-8$ days before delivery (arrows) in (a) an intact ewe and (b) a pinealectomized ewe. The solid horizontal bars represent the periods of darkness. (Reprinted with permission from McMillen and Nowak, 1989.)

transplacental signal acts to generate or entrain daily or seasonal rhythms in fetal behaviour and hormone concentrations. Here we discuss the evidence that the daily rhythm in melatonin concentrations plays such a role during late pregnancy.

\section{Maternal Melatonin and Daily Rhythms in Fetal Behaviour}

There is a diurnal rhythm in the incidence of fetal breathing movements in sheep that occurs in association with a rhythm in the incidence of low voltage electrocortical activity (Boddy et al., 1973; Callea et al., 1990). The origin of the $24 \mathrm{~h}$ rhythm in fetal breathing movements is unknown and it appears that this rhythm is not a consequence of the maternal feeding regimen or of diurnal changes in plasma glucose or prostaglandin concentrations (Callea et al.; 1990). We found that a shift in the time of onset of darkness was associated with a shift in the phase of the daily rhythm of fetal breathing movements (McMillen and Walker, 1991). In ewes kept in a $12 \mathrm{~h}$ photoperiod, the peak incidence in fetal breathing movements occurred just before and immediately after the onset of darkness when the lights were switched off at either 19:00 h (defined as a 'normal' lighting regimen) or at 11:00 h (defined as an 'altered' lighting regimen) (Fig. 2). In this study the maternal and fetal plasma concentrations of melatonin were higher throughout the period of darkness, independent of the clock time of dark onset (McMillen and Walker, 1991). We have also reported that maternal pinealectomy, which abolishes the nocturnal increase in fetal melatonin, alters the daily pattern of fetal breathing in sheep (McMillen et al., 1990). In contrast to intact ewes, there was no late afternoon-early evening peak in the incidence of fetal breathing movements preceding the onset of darkness in a group of pinealectomized ewes (McMillen et al., 1990). We used pinealectomized pregnant ewes to investigate the effects of separately altering the time of dark onset and the timing of melatonin replacement on the phase of the daily rhythm in fetal breathing movements (Houghton ef al., 1993).

Pinealectomized pregnant ewes were held under a normal lighting regimen (i.e. $12 \mathrm{~h}$ photoperiod; lights off at 19:00 h) until 135 days gestation (term $=145 \pm 3$ days gestation) and then in an altered lighting regimen (i.e. $12 \mathrm{~h}$ photoperiod; lights off at 11:00 h) until 145 days gestation. Half of the ewes were infused with melatonin $\left(12-15 \mu \mathrm{g} \mathrm{h}^{-1}\right.$ i.v.) from $11: 00 \mathrm{~h}$ for $12 \mathrm{~h}$ each day between 125 and 135 


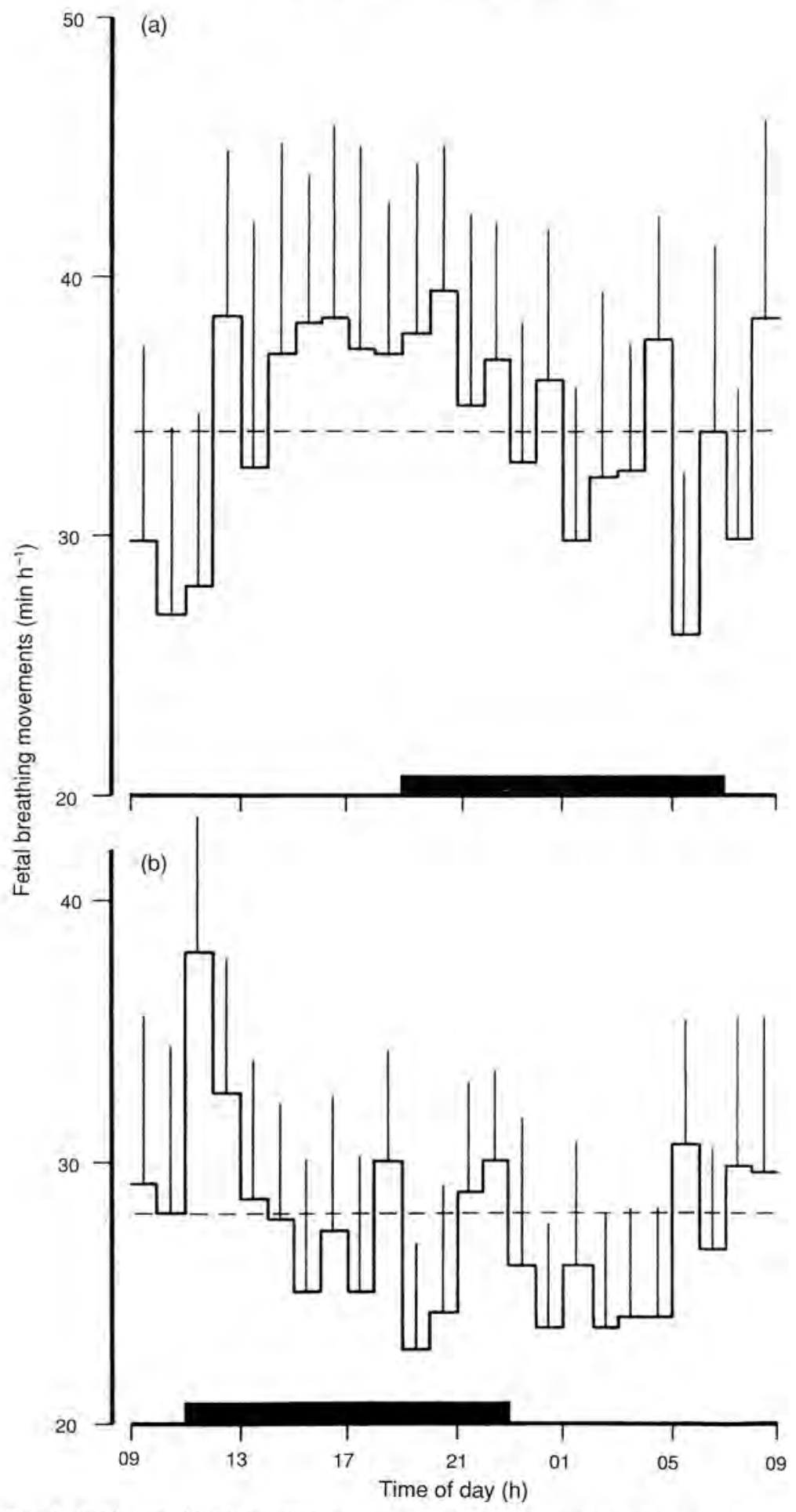

Fig. 2. Incidence of fetal breathing movements (minutes spent breathing per hour) expressed as the means \pm SEM during a $24 \mathrm{~h}$ cycle in a group of ewes (a) held under normal lighting and (b) held under an altered lighting regimen. The period of darkness is shown by the solid horizontal bars. (Reprinted with permission from McMillen and Walker, 1991.) 
(a)

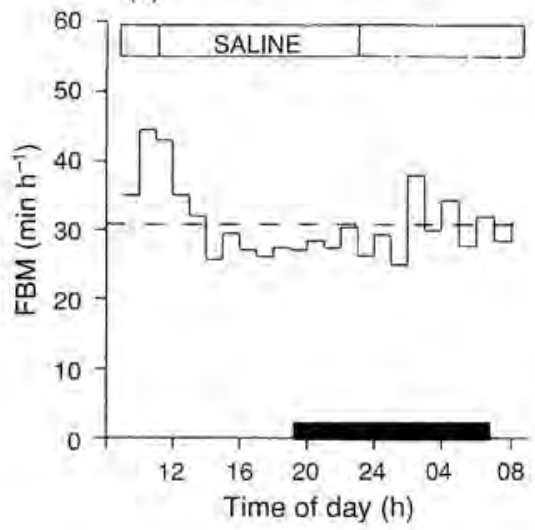

(c)

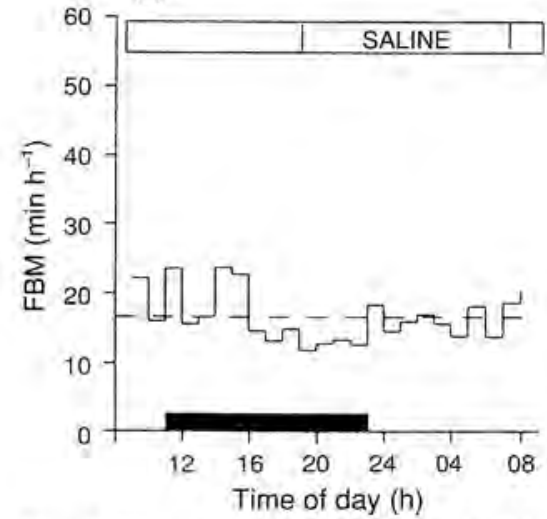

(b)

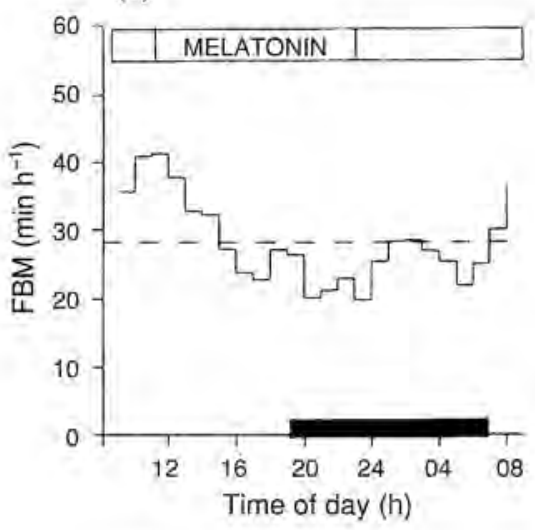

(d)

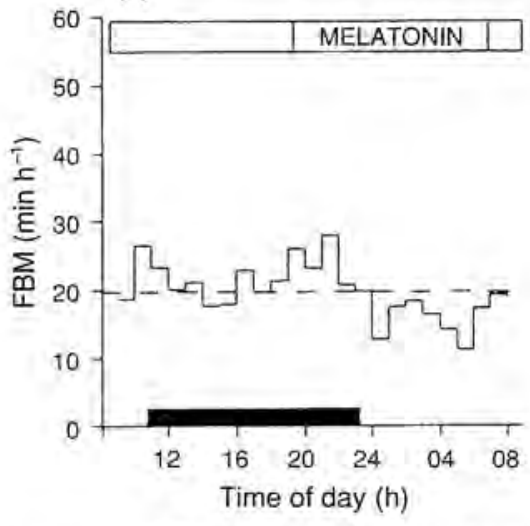

Fig. 3. The mean incidence of fetal breathing movements (FBM: minutes spent breathing per hour) in a group of pinealectomized ewes during a $24 \mathrm{~h}$ cycle in normal lighting (a), (b) and altered lighting (c), (d). The open bars represent the $12 \mathrm{~h}$ i, p. infusion period when either saline ((a) and (c)) or melatonin ((b) and (d)) was infused. The period of darkness during each lighting regimen is shown by the solid horizontal bar. (Reprinted with permission from Houghton et al., 1993.)

days gestation while in the normal lighting regimen and from 19:00 $\mathrm{h}$ each day while in the altered lighting regimen. The remaining half of the pinealectomized ewes were infused with saline.

In the normal lighting regimen (i.e. lights off at 19:00 h) the peak incidence in fetal breathing movements occurred at between 11:00 h and 13:00 h in the ewes infused with either melatonin or saline from $11: 00 \mathrm{~h}$ (Fig. 3). In the altered lighting conditions (i.e. lights off at 11:00 h) there was no $24 \mathrm{~h}$ variation in the incidence of fetal breathing movements in the saline-infused ewes but a significant daily variation in fetal breathing movements was present in the melatonin-infused group with a peak incidence occurring at 19:00-22:00 h (Fig. 3). It is important to note that the $24 \mathrm{~h}$ profile of fetal breathing movements in the pinealectomized ewes held in altered lighting conditions and infused with melatonin from 19:00 h was similar to the diurnal profile of fetal breathing movements in pineal intact ewes kept under normal lighting conditions (i.e. lights off at 19:00 h). These findings strongly indicate that melatonin can generate and entrain the early evening peak in the incidence of fetal breathing movements and are consistent with the hypothesis that melatonin may be a circadian signal providing the fetus with information about the time of day. The mechanisms by which melatonin could exert such an effect are unclear. One possibility is that the normal daily variation in fetal breathing activity represents an endogenous rhythm generated by the fetal circadian pacemakers, the suprachiasmatic nuclei (SCN), in 


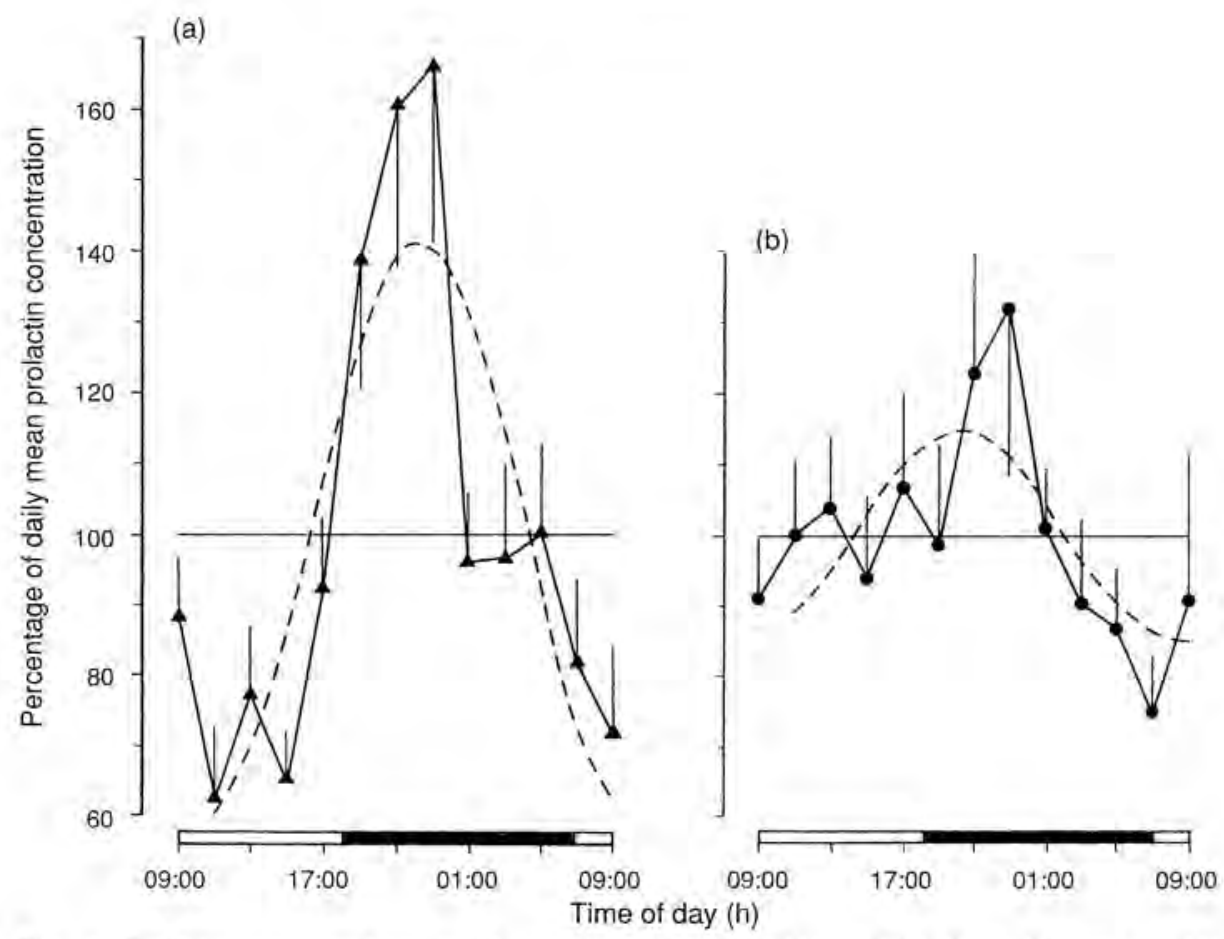

Fig. 4. Prolactin concentrations in (a) pregnant ewes $(n=13)$ and (b) sheep fetuses $(n=13)$ expressed as a percentage of the daily mean prolactin concentrations and plotted against time of day. The solid horizontal bars represent the periods of darkness. The dashed lines represent the sinusoidal curves with a $24 \mathrm{~h}$ period which significantly fitted the maternal and fetal hormonal data. (Reprinted with permission from McMillen et al., 1987.)

the fetal hypothalamus. It has been shown in rats that dams entrain the activity pattern of neurones in the fetal SCN to the external light-dark cycle (Reppert and Schwartz, 1986a). It has been found that while maternal pinealectomy does not abolish the maternal entrainment of fetal SCN activity in rats (Reppert and Schwartz, 1986b), melatonin binding sites are present in the SCN of the adult and fetal hypothalami (Reppert et al., 1988). It is therefore possible that maternal melatonin modulates fetal breathing via an action at the endogenous circadian pacemakers within the fetal brain.

\section{Maternal Melatonin and Daily Rhythms in Fetal Prolactin Concentrations}

Several studies in pregnant and nonpregnant sheep have indicated that there is a peak in the plasma concentrations of prolactin associated with the time of lights off or dusk (Brinklow and Forbes, 1984; Poulton et al., 1986; McMillen et al., 1987; Walton et al., 1989). It has also been demonstrated that there is a daily rhythm in the plasma concentrations of prolactin in sheep fetuses throughout late gestation (McMillen et al, 1987; Seron-Ferre et al, 1989) (Fig. 4). The daily rhythm in maternal and fetal prolactin concentrations persists after pinealectomy of pregnant ewes, which suggests that the generation of this hormonal rhythm does not depend on the neuroendocrine actions of melatonin (McMillen et al, 1991). However, there is evidence that the phase of the daily prolactin rhythm in ewes and fetuses alters with season (Seron Ferre et al., 1989) and with a change in the time of onset of darkness (McMillen and Walker, 1991), We have used pinealectomized pregnant ewes to investigate the effects of separately altering the time of dark onset and the timing of melatonin replacement on the phase of the daily rhythm in maternal and fetal prolactin concentrations (Houghton et al., 1993). The daily variation in maternal prolactin concentrations in the pinealectomized ewes was not affected by changes in the time of onset 
(a)

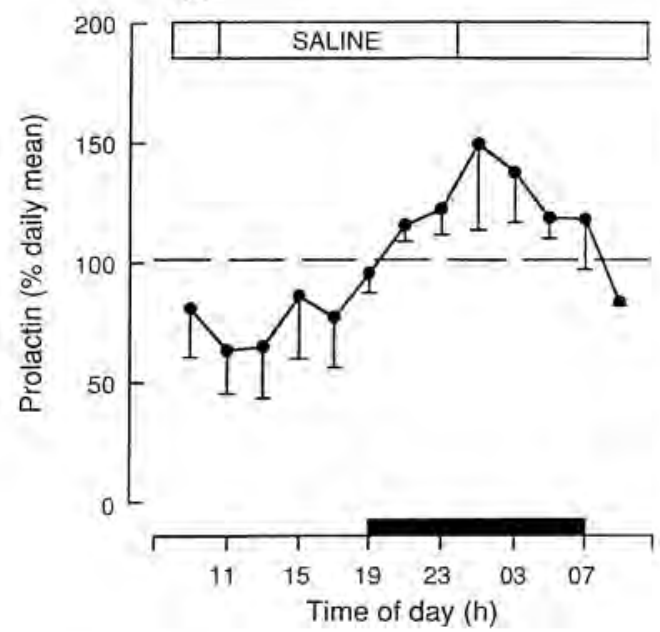

(c)

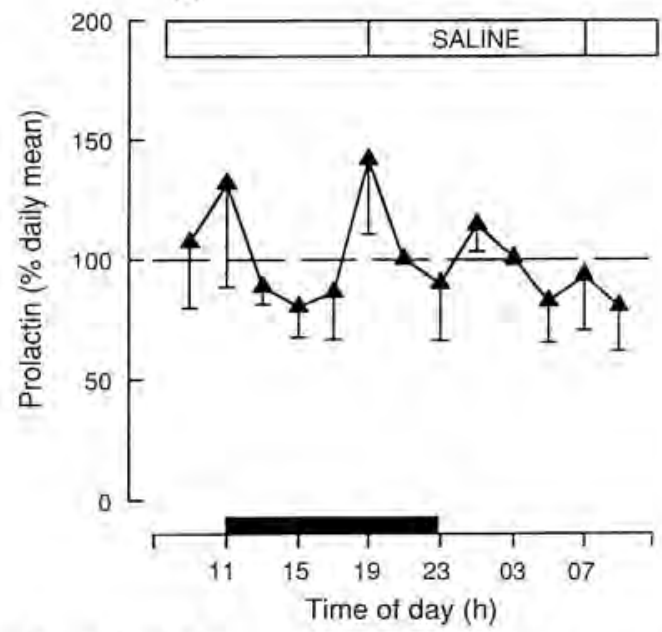

(b)

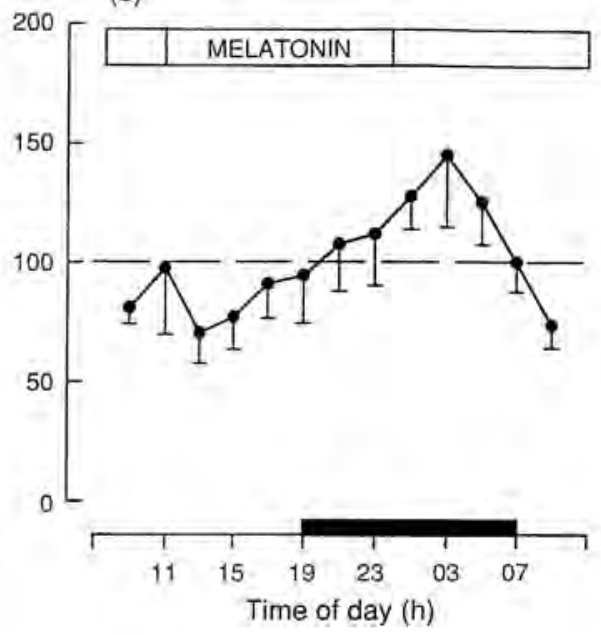

(d)

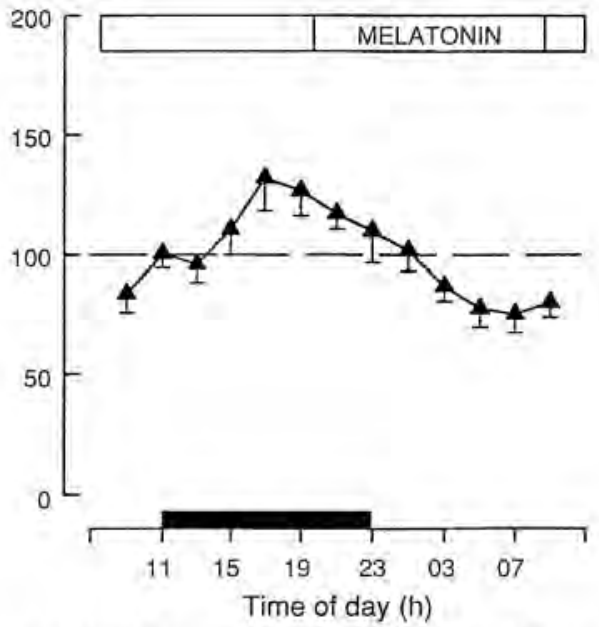

Fig. 5. Fetal plasma prolactin concentrations (percentage of the daily mean) in a group of pinealectomized ewes, expressed as means \pm SEM in normal lighting ((a) and (b)) and altered lighting ((c) and (d)) regimens during a $24 \mathrm{~h}$ cycle. The open bars represent the $12 \mathrm{~h}$ f.v. infusion period when either saline $((a)$ and $(c))$ or melatonin ((b) and (d)) were infused. The period of darkness during each lighting regimen is shown by the solid horizontal bar. (Reprinted with permission from Houghton et al, 1993.)

of melatonin infusion, but was significantly different in the normal and the altered lighting regimens. In the normal lighting regimen (lights off at 19:00 h), maternal prolactin concentrations were highest at $21: 00 \mathrm{~h}\left(56.2 \pm 21.6 \mathrm{ng} \mathrm{ml}^{-1}\right)$, whereas in the altered lighting conditions, the peak in maternal prolactin occurred at $17: 00 \mathrm{~h}\left(90.4 \pm 25\right.$. I ng ml $\left.{ }^{-1}\right)$. Similarly, the daily variation in fetal prolactin concentrations was also not affected by changes in the time of onset of the melatonin infusion, but was different in each of the two lighting regimens. In the normal lighting regimen, fetal prolactin reached a peak $\left(13.0 \pm 3.7 \mathrm{ng} \mathrm{ml}^{-1}\right)$ at 01:00-03:00 h, whereas in the altered lighting regimen the peak $\left(29.2 \pm 9.8 \mathrm{ng} \mathrm{ml}^{-1}\right.$ ) occurred at 17:00-21:00 h (Houghton et al., 1993) (Fig, 5).

A shift in the timing of the daily peak in maternal prolactin concentrations in response to the altered lighting regimen occurred in the pinealectomized ewes and this indicates that in ewes, prolactin secretion 
can respond to changes in the external light-dark cycle in the absence of a pineal gland. The timing of the daily peak in fetal prolactin concentrations shifted in parallel with the daily peak in maternal prolactin when the ewes were moved into altered lighting. This raises the possibility that either the fetus perceives the changes in the external light-dark cycle or that there is an unknown factor which transmits information about the external light-dark cycle to the fetal hypothalamo-pituitary axis in the absence of the maternal pineal gland.

In these studies in pineal intact and pinealectomized ewes, maternal and fetal plasma concentrations of prolactin were higher in the altered lighting regimen than in the normal lighting regimen. In intact ewes in the altered light conditions (i.e. lights off at 11:00 h), the mean $24 \mathrm{~h}$ plasma prolactin concentrations were $115.2 \pm 57.6 \mathrm{ng} \mathrm{ml}^{-1}$ (maternal) and $28.8 \pm 6.1 \mathrm{ng} \mathrm{ml}^{-1}$ (fetal), whereas in the normal light conditions (i.e. lights off at 19:00 h), the corresponding concentrations were $26.2 \pm 11.4 \mathrm{ng} \mathrm{ml}^{-1}$ (maternal) and $13.0 \pm 3.9 \mathrm{ng} \mathrm{ml}^{-1}$ (fetal). In the pinealectomized ewes held in altered light conditions, the mean $24 \mathrm{~h}$ plasma prolactin concentrations were $71.7 \pm 7,7 \mathrm{ng} \mathrm{ml} \mathrm{m}^{-1}$ (maternal) and $24.6 \pm 2.4 \mathrm{ng} \mathrm{ml}{ }^{-1}$ (fetal) and in the normal lighting regimen, prolactin values were $38.9 \pm 4.8 \mathrm{ng} \mathrm{ml}^{-1}$ (maternal) and $8.4 \pm 0.7 \mathrm{ng} \mathrm{ml}^{-1}$ (fetal). Maternal and fetal prolactin concentrations were higher during the altered lighting regimen in pinealectomized ewes irrespective of whether melatonin was infused. It may be, therefore, that the central mechanisms that control the daily secretion of prolactin in ewes and fetuses are sensitive to the direct or indirect effects of light or dark falling at a particular phase of an endogenously derived diumal cycle of stimulation of prolactin secretion. Although it appears from the studies to date that melatonin has a relatively minor role in the generation of this diurnal rhythm, the degree of interaction between the phase of the daily melatonin rhythm and the phase of the daily prolactin rhythm has not been exhaustively investigated in ewes or fetuses. The results outlined above suggest that there are several neuroendocrine mechanisms involved in the transmission of information about the time of day to the sheep fetus in late gestation.

\section{Maternal Melatonin and Seasonal Rhythms in Fetal Prolactin Concentrations}

Although it appears that maternal melatonin does not generate or entrain the daily rhythm in fetal prolactin concentrations, it has been shown that seasonal changes in the duration of the external photoperiod are associated with changes in the fetal plasma concentrations of prolactin (Bassett et al, 1988; Seron-Ferre et al., 1989). Fetal prolactin concentrations increase after pinealectomy of pregnant ewes (McMillen et al., 1991) and it has been demonstrated that when melatonin is infused into intact pregnant ewes during summer pregnancies to simulate the winter duration of the nocturnal melatonin increase, there is an associated reduction in the fetal and maternal plasma concentrations of prolactin (Bassett et al, 1989), It is clear, therefore, that the duration of the nocturnal melatonin signal provides adult and fetal sheep with photoperiodic information. However, the neuroendocrine changes that link melatonin to the synthetic or secretory changes in the fetal pituitary lactotrophs are poorly understood. We have recently investigated whether there are differences in the fetal plasma concentrations of melatonin and prolactin in ewes held in long and short external photoperiods after surgical disconnection of the fetal hypothalamus and pituitary. Fetal hypothalamo-pituitary disconnection or sham operations were carried out at aboul day 110 of gestation in a group of 23 pregnant ewes. Pregnant ewes or intact sheep fetuses were exposed to either a long light (LL; I6 h light: $8 \mathrm{~h}$ dark) or a short light (SL; $8 \mathrm{~h}$ light:16 h dark) regimen until day 143 of gestation (Houghton et al,, in press).

\section{Effect of hypothalamo-pituitary disconnection on fetal melatonin thythms}

There was an increase in maternal melatonin concentrations during the dark phase in each lighting regimen in ewes carrying hypothalamo-pituitary disconnected or intact sheep fetuses. In the short light regimen, there was also a significant increase in fetal melatonin concentrations during the dark phase in the hypothalamo-pituitary disconnected and intact groups. In the short light regimen, there was no difference between the two treatment groups in the mean plasma concentrations of melatonin in the dark phase (intact: $241.7 \pm 47.1 \mathrm{pmol} \mathrm{I}^{-1}$ : hypothalamo-pituitary disconnected; $204.3 \pm 51.5 \mathrm{pmol} \mathrm{I}^{-1}$ ). 
However, under long light conditions, fetal melatonin concentrations were increased only during the dark phase in the intact and not the hypothalamo-pituitary disconnected group. In the long light regimen, the mean plasma melatonin concentrations during the dark phase were higher in intact fetal sheep $\left(165.7 \pm 46.2 \mathrm{pmol} \mathrm{I}^{-\mathrm{I}}\right.$ ) than in the hypothalamo-pituitary disconnected group $(66.9 \pm 17.3 \mathrm{pmol}$ $1^{-1}$ ). These data indicate that the fetal hypothalamo-pituitary disconnection procedure resulted in the loss of a source of circulating fetal melatonin during the dark phase in the long light conditions (Houghton et al., in press). During the fetal hypothalamo-pituitary disconnection procedure, the optic chiasma is separated and the fetal SCN is destroyed. It is possible, therefore, that the loss of the nocturnal increase in fetal melatonin under the long light conditions after hypothalamo-pituitary disconnection may have been a consequence of ablation of these fetal circadian pacemakers. We have previously demonstrated that the pineal gland of the lamb fetus has the capacity to synthesize and secrete melatonin in response to $\beta$-adrenergic stimulation during the last 10 days of gestation (McMillen et al., 1989). If there is a fetal source of melatonin, then it is difficult to explain the lack of effect of fetal hypothalamo-pituitary disconnection on fetal melatonin concentrations under short light conditions. Perhaps the sustained nocturnal increase in maternal melatonin during the $16 \mathrm{~h}$ dark phase effectively 'masks' or suppresses any fetal source of melatonin. As discussed above, we have previously found that maternal pinealectomy effectively abolishes fetal melatonin rhythms during $12 \mathrm{~h}$ photoperiodic conditions throughout late gestation. It is therefore necessary to speculate that any fetal hypothalamic control of melatonin secretion is in turn dependent on a maternal melatonin signal. Further experiments are clearly required to define the contribution of the fetal pineal gland to the daily rhythm in fetal melatonin concentrations during long and short lighting regimens.

\section{Effect of hypothalamo-pitutiary disconnection on fetal prolactin rhythms}

We found that the mean fetal prolactin concentrations throughout late gestation were significantly higher in long light conditions (hypothalamo-pituitary disconnected: $37.3 \pm 11.3 \mathrm{ng} \mathrm{ml}{ }^{-1}$; intact: $71.0 \pm 16.2 \mathrm{ng} \mathrm{ml}^{-1}$ ) than in the short light regimen (hypothalamo-pituitary disconnected: $9.0 \pm 4.8 \mathrm{ng} \mathrm{ml}^{-1}$; intact: $34.2 \pm 4.8 \mathrm{ng} \mathrm{ml}^{-1}$ ) (Houghton et al., in press). We have therefore found that there was a relationship between the duration of the external photoperiod and prolactin concentrations throughout late gestation in sheep fetuses, in which the fetal pituitary was disconnected from the fetal hypothalamus. In most species the prolactin inhibitory factor is considered to be dopamine and one hypothesis is that low prolactin in short daylengths is due to increased dopaminergic suppression of prolactin release from the pituitary lactotroph (Curlewis, 1992). A series of studies has found that dopamine turnover in the median eminence and mediobasal hypothalamus/arcuate nucleus is either decreased (Steger et al., 1983; Glass et al., 1988; Zinn et al., 1991) or remains unchanged (Thiery, 1991) during short photoperiods. However, in our study we found that after hypothalamo-pituitary disconnection there was no fetal prolactin response to administration of a dopaminergic antagonist, chlorpromazine. This clearly indicates that in the hypothalamo-pituitary disconnected group, there was no influence of dopamine either extrahypothalamic or derived from the median eminence on prolactin secretion in either light regimen. This suggests that the effects of external photoperiod and changes in maternal melatonin on fetal prolactin secretion are not mediated via changes in dopaminergic inhibition of pituitary function acting through the hypothalamus. Recently, a series of studies in adult sheep has confirmed the finding that the relationship between circulating prolactin and external photoperiod is maintained after hypothalamo-pituitary disconnection (Lincoln and Clarke, 1994).

One possible extrahypothalamic site of action of melatonin is the pars tuberalis of the fetal pituitary. There is considerable indirect evidence that the pars tuberalis may be important in mediating seasonal reproductive responses to melatonin. In all mammals, the pars tuberalis, unlike the pars distalis, contains exceptionally high concentrations of iodomelatonin binding sites (Morgan et al., 1989; Krause and Dubocovich, 1990). Most of the secretory cell types in the ovine pars tuberalis are agranular and it appears that these cells are melatonin responsive (Morgan et al, 1991). A secretory product of the fetal pars tuberalis may therefore influence prolactin synthesis and secretion in the pars distalis and the output of this product may be inversely related to the duration of the nocturnal surge of maternal melatonin concentrations. 
In these studies we also found that there was a significant interaction between the effects of fetal surgical treatment and the effect of time of day on fetal prolactin concentrations. In the intact group there was a significant variation in fetal prolactin with respect to time of day, which was similar in each lighting regimen. In the intact fetal sheep, fetal prolactin concentrations were higher at 13:00 h and at 17:00 $\mathrm{h}$ than between 03:00 $\mathrm{h}$ and 07:00 $\mathrm{h}$. In contrast, in the hypothalamo-pituitary disconnected sheep fetuses there was no significant effect of time of day on fetal prolactin concentrations in either the long or the short lighting regimens.

It is therefore clear that the presence of an intact and functional hypothalamus is essential for the generation of the daily prolactin rhythm under both lighting regimens. There are very few studies that have investigated the source and control of the daily prolactin rhythm in either the adult or fetal sheep. Pau et al. (1984) reported that frontal hypothalamic deafferentation did not alter the photoperiodinduced changes in the $24 \mathrm{~h}$ profiles of prolactin in adult ewes. These authors concluded that the direct neural pathways between the suprachiasmatic-preoptic region and the mediobasal hypothalamus must play a relatively minor role in the generation of the daily prolactin rhythm. The hypothalamic site of the generation of the daily prolactin rhythm in fetuses and ewes and the nature of the inputs to this site therefore remain to be established.

\section{Conclusion}

During the past five years it has become clear that the fetus is exposed to a number of external cues that provide it with information about the time of day and duration of the photoperiod. There is evidence that the daily melatonin rhythm is one of these cues and that this maternal signal may generate and entrain a number of daily fetal rhythms. We have also presented indirect evidence that the maternal melatonin rhythm may have a role in the generation of a fetal melatonin rhythm. It is clear that there is a relationship between the duration of the external photoperiod, the duration of the nocturnal melatonin surge and circulating prolactin concentrations before birth. It also appears that melatonin may act at an extrahypothalamic site, perhaps the pars tuberalis, to control the seasonal prolactin rhythm before and after birth. The interaction of the hypothalamus, pars tuberalis and pars distalis in the generation of the seasonal rhythm in prolactin concentrations and the role of the seasonal prolactin rhythm in synchronizing key events in the growth and development of the late gestation fetus will be major areas for future investigation in developmental neuroendocrinology.

\section{References}

Bassett JM, Bomford J and Mott JC (1988) Photoperiod an important regulator of plasma prolactin concentrations in fetal lambs in late gestation Quarterly Journal of Experimental Physiology 73 241-245

Bassett JM, Curtis N, Hanson C and Weeding CM (1989) Effects of altered photoperiod or matemal melatonin administration on plasma prolactin concentrations in fetal lambs Journal of Endocrinology 122 633-643

Boddy K, Dawes GS and Robinson JS (1973) A 24 hr rhythm in the fetus. In Foetal and Neonatal Physiology. Proceedings of the Barcrofl Symposium pp 63-66 Eds K Cross, R Comline, GS Dawes and P Nathanielsz. Cambridge University Press, Cambridge

Brinklow BR and Forbes JM (1984) The effect of short and long photoperiods on the plasma concentrations of prolactin and cortisol in sheep Reproduction Nutrition and Development 24 $107-116$

Callea 1, McMillen IC and Walker DW (1990) Effect of feeding regime on diurnal variation of breathing movements in late gestation fetal sheep Jourial of Applied Physiology 68 $1786-1792$
Curlewis JD (1992) Seasonal prolactin secretion and its role in seasonal reproduction: a review Reproduction Fertility and Development 4 1-23

Glass JD, Ferreira S and Weaver DR (1988) Photoperiodic adjustments in hypothalamic amines, gonadotropin releasing hormone and $\mathrm{B}$ endorphin in the white footed mouse Endocrinology $1231119-1127$

Houghton DC. Walker DW, Young IR and McMillen IC (1993) Melatonin and the light/dark cycle separately influence daily behavioural and hormonal rhythms in the pregnant ewe and sheep fetus Endocrinology 133 90-98

Houghton DC, Young IR and McMillen IC Evidence for hypothalamic control of the diurnal rhythms in prolactin and melatonin in the fetal sheep during late gestation Endocrinology (in press)

Krause DN and Dobocovich ML (1990) Regulatory sites in the melatonin system of mammals. Trends in the Neturosciences $13464-470$

Lincoln GA and Clarke IJ (1994) Photoperiodically induced cycles in the secretion of prolactin in hypothalamopituitary disconnected rams: evidence for translation of 
the melatonin signal in the pituitary gland Journal of Neuroendocrinology 6 25I-260

McMillen IC and Nowak R (1989) Maternal pinealectomy abolishes the diurnal rhythm in plasma melatonin concentrations in the fetal sheep and pregnant ewe during late gestation Journal of Endocrinology $120459-464$

McMillen IC and Walker DW (I991) Effects of different lighting regimes on daily hormonal and behavioural rhythms in the pregnant ewe and sheep fetus Journal of Physiology $\mathbf{4 4 2}$ $465-476$

McMillen IC, Thorburn GD and Walker DW (1987) Diurnal variations in plasma concentrations of cortisol, prolactin, growth hormone and glucose in the fetal sheep and pregnant ewe during late gestation Journal of Endocrinology $11465-72$

McMillen IC, Parkington HC and McCance IC (I989) The effect of isoprenaline on the melatonin output from the fetal and newborn lamb pineal gland in vitro Acta Endocrinologica Scandinavica $121773-776$

McMillen IC, Nowak R, Walker DW and Young IR (1990). Maternal pinealectomy alters the daily pattern of fetal breathing in sheep American Joumal of Physiology 258 R.284-287

McMillen IC, Walker DW, Young IR and Nowak R (1991) A daily prolactin rhythm persists in the ewe, foetus and newborn lamb after maternal pinealectomy in late gestation Journal of Neuroendocrinology 3 369-374

Morgan PJ, Williams LM, Davidson G, Lawson W and Howell E (1989) Melatonin receptors on ovine pars tuberalis: characterisation and autoradiographical localization Jourtal of Neuroendocrinology 122 633-642

Morgan PJ, King TP, Lawson W, Slater D and Davison G (1991) Ultrastructure of melatonin-responsive cells in the ovine pars tuberalis Cell and Tissue Research $263 \quad 529-534$

Pau K-YF and Jackson GL (1984) Effect of frontal hypothalamic deafferentation on photoperiod induced changes in the secretion of prolactin in the ewe Endocrinology 115 $1663-1671$

Poulton AL, English J, Symons AM and Arendt J (1986) Effects of various melatonin treatments on plasma prolactin concentrations in the ewe Journal of Endocrinology 108 $287-292$
Reppert SM and Schwartz WJ (1986a) The maternal suprachiasmatic nuclei are necessary for maternal coordination of the developing circadian rhythm Joumal of Neuroscience 6 2724-2729

Reppert SM and Schwartz WJ (1986b) Maternal endocrine extirpations do not abolish maternal coordination of the fetal circadian clock Endocrinology 119 1763-1767

Reppert SM, Weaver DR, Rivkees SA and Stopa EG (1988) Putative melatonin receptors in a human biological clock Science 242 78-81

Seron-Ferre M, Vergara M, Parraguez VH, Riquelme R and Llanos AJ (1989) The circadian variation of prolactin in fetal sheep is affected by the seasons Endocrinology 125 1613-1616

Steger RW, Bartke A, Goldman BD, Soares MJ and Talamantes F (1983) Effects of short photoperiod on the ability of golden hamsters to secrete prolactin and gonadotropins in vitro Biology of Reproduction 29 872-878

Thiery JC (1991) Monoamine contents of the stalk-median eminence and hypothalamus in adult female sheep as affected by daylength Journal of Neuroendocrinology 3 407-411

Walton JS, Evins JD, Fitzgerald BP and Cunningham FJ (1989) Abrupt decrease in day length and short term change in the plasma concentrations of $\mathrm{FSH}, \mathrm{LH}$ and prolactin in anoestrous ewes Joumal of Reproduction and Fertility $\mathbf{5 9}$ 163-171

Yellon SM and Longo LD (1987) Melatonin rhythms in fetal and maternal circulation during pregnancy in sheep American Joumal of Physiology 252 E799-E802

Yellon SM and Longo LD (1988) Effect of maternal pinealectomy and reverse photoperiod on the circadian melatonin thythm in the sheep and fetus during the last trimester of pregrancy Biology of Reproduction 39 1093-1099

Zemdegs IZ, McMillen IC, Walker DW, Thorburn GD and Nowak R (1988) Diurnal rhythms in plasma melatonin concentrations in the fetal sheep and pregnant ewe during late gestation Endocrinology 123 284-289

Zinn SA, Chapin LT, Lookingland KJ, Moore KE and Tucker HA (1991) Effects of photoperiod on lactotrophs and on dopaminergic and 5-hydroxytryptaminergic neurones in bull calves lournal of Endocrinology 129 141-148 